\title{
UNDERSTANDING THE EFFECTS OF ALKALI PRETREATMENT AND ACID TREATMENT OF OIL PALM TRUNK FIBRES
}

\author{
BALQIS AZ-ZAHRAA NORIZAN, ${ }^{*}$ NUR SYAFIQAH SAUTA, ${ }^{*}$ SHARIFAH NURUL AIN SYED \\ HASHIM, ${ }^{*}$ SARANI ZAKARIA, ${ }^{*}$ MUHAMMAD FAUZI DAUD, ${ }^{* *}$ BABUL-AIRIANAH OTHMAN ${ }^{* * *}$ \\ and SHARIFAH NABIHAH SYED JAAFAR" \\ "Bioresources and Biorefinery Laboratory, Faculty of Science and Technology, Universiti Kebangsaan \\ Malaysia, 43600 UKM Bangi, Selangor, Malaysia \\ ${ }^{*}$ Universiti Kuala Lumpur, Institute of Medical Science Technology, \\ 43000 Kajang, Selangor, Malaysia \\ ${ }^{* * *}$ Plant Biochemistry Laboratory, Faculty of Science and Technology, Universiti Kebangsaan Malaysia, \\ 43600 UKM Bangi, Selangor, Malaysia \\ ๔orresponding author: Sharifah Nabihah Syed Jaafar, nabihah@ukm.edu.my
}

Cellulose is becoming a super-material due to its excellent properties and renewability. Understanding its resistance to chemical treatments is important to boost the usage and accessibility. In this study, oil palm trunk fibre (OPTF) was pretreated with $\mathrm{NaOH}$ and $\mathrm{NH}_{4} \mathrm{OH}$ either in an autoclave or in a water bath. The optimised alkaline pretreated samples were then subjected to acid treatment with acetic acid (AA). The results showed the highest delignification was achieved by using $12 \%$ of $\mathrm{NaOH}$ via the autoclaving process, with $10685.4 \mathrm{mg} / \mathrm{L}$ of lignin and $7.8 \%$ of acid insoluble lignin (AIL). The Fourier-transform infrared (FTIR) analysis confirmed the removal of lignin by the reduction of the peaks at 1250 and $1750 \mathrm{~cm}^{-1}$, representing $\mathrm{C}=\mathrm{O}$ and $\mathrm{C}-\mathrm{O}-\mathrm{C}$, respectively, from lignin. The delignification was pronounced when concentrated AA was used and the lignin-to-cellulose ratio decreased to about $52 \%$. Other than lignin, amorphous celluloses were also removed during the AA treatment, causing an increment in the crystallinity index (CrI) and crystallite size (L). Consequently, the AA treatment had led to the depolymerisation of crystalline cellulose and affected the viscosity-average molecular weight $\left(\mathrm{M}_{\eta}\right)$.

Keywords: lignin, cellulose, crystallinity index, peak area ratio, viscosity-average molecular weight

\section{INTRODUCTION}

Cellulose can be turned into valuable products and is considered a sustainable green material. Some of the products made from cellulose include filter membranes, ${ }^{1}$ hydrogels, ${ }^{2}$ food additives, ${ }^{3}$ pharmaceuticals, ${ }^{4}$ microspheres ${ }^{5}$ and composites. ${ }^{6}$ In Malaysia, generating cellulose from oil palm trunk fibre (OPTF) will be economical because it is an eco-rich source; the oil palm biomass accounts for $85.5 \%$ wastes every year. ${ }^{7}$ The National Biomass Strategy 2020 hopes this waste could be channelled into higher value uses and increase the gross national income (GNI) of the country. Moreover, utilising OPTF waste into valuable products may reduce the carbon dioxide sequestration from the atmosphere. Substantially, the development of cellulose extraction that is environmentally friendly and produces zero pollution should be imposed.

Biomass comprises three complex organic polymers, namely, cellulose, hemicellulose and lignin. The biomass is primarily found in the plant cell wall, with lignin concentrated in the outer part of the cell wall, cellulose within the lignin shells, and hemicellulose within the cellulose and between the cellulose and lignin. ${ }^{8}$ These complex organic polymers are strongly linked to one another through hydrogen and covalent bonds to form a complex molecular organisation in lignocellulosic biomass. For instance, cellulose and lignin are attached together primarily through the ether bond. ${ }^{9}$ Out of the three complex organic polymers, cellulose has favourable properties, such as hydrophilicity, chirality, versatile semicrystallinity, and great stiffness. ${ }^{10}$ There are intraand intermolecular hydrogen bonds in cellulose, as well as between the hydroxyl group and cyclic oxygen that are linked by $\beta-1,4$-glycosidic bonds, ${ }^{11}$ contributing to the crystalline and amorphous structures in cellulose.

Cellulose Chem. Technol., 53 (9-10), 1001-1008(2019) 
Cellulose has a specific structure due to its dense hydrogen-bond network, causing it to be resistant to chemical transformations. ${ }^{12}$ Therefore, various treatment methods have been reported to break the tight hydrogen-bond network for chemical transformation, for example, using biological processes, ${ }^{13}$ steam pressure, ${ }^{14}$ acid hydrolysis, ${ }^{15}$ alkaline hydrolysis, ${ }^{16}$ liquid hot water extraction, ${ }^{17}$ and ammonia treatment. ${ }^{18}$ Concentrated and strong chemical treatment has been used to enhance the disruption of the biomass. This treatment helps to cleave the complex bonding between and within the cellulose, lignin and hemicellulose, making the biomass more accessible. ${ }^{19}$ However, such a method can be costly and hazardous because of the toxic and corrosive nature of the chemicals used. $^{20}$ As such, mild and dilute chemical treatment has become an attractive alternative for biomass modification.

On the other hand, heat transfer is also introduced during the modification either by convection, conduction or radiation. ${ }^{21}$ Moreover, the use of high technology treatment of biomass, such as microwave, ultrasound and high voltage electrical discharge, has gained considerable attention nowadays. The purpose is to enhance the efficiency of conventional treatments and minimise the environmental impacts and energy consumption. For example, sorghum stalk treated with $1 \% \mathrm{NaOH}$ under autoclaving at $121{ }^{\circ} \mathrm{C}$ and 15 psi for 30 min has shown the lowest acidinsoluble lignin content with only $2.1 \%{ }^{22}$ Meanwhile, Nomanbhay et $\mathrm{al}^{23}$ have succeeded in removing $74 \%$ of lignin from oil palm empty fruit bunch fibre by using the microwave treatment. This is because the microwave treatment provides energy efficiency to the process, in which electromagnetic radiation is directed to the biomass, thus generating uniform heat. ${ }^{24}$ In this study, the changes in the physical and chemical behaviours of the OPTF have been investigated during the alkali and acid treatments. It is believed that the proposed procedure is simple enough and the obtained solid containing the cellulosic part has a potential for industrial application.

\section{EXPERIMENTAL}

Materials and chemicals

OPTF was obtained from Leong Brothers Earthworks Construction, Kluang, Johor; while the standard soda lignin, sodium hydroxide $(\mathrm{NaOH})$, ammonium hydroxide $\left(\mathrm{NH}_{4} \mathrm{OH}\right)(30 \%)$, acetic acid
$\left(\mathrm{CH}_{3} \mathrm{COOH}\right)$ (99\%), sulfuric acid $\left(\mathrm{H}_{2} \mathrm{SO}_{4}\right)(72 \%)$, ethylenediamine $\left(\mathrm{C}_{2} \mathrm{H}_{8} \mathrm{~N}_{2}\right)$ (99\%), cadmium oxide $(\mathrm{CdO})$ were purchased from Sigma-Aldrich.

\section{Alkali pretreatment}

The OPTF was washed with ethanol, acetone and distilled water thoroughly and dried overnight in an oven at $105{ }^{\circ} \mathrm{C}$. The fibre was ground to powder. About $2.5 \mathrm{~g}$ of the powder was mixed in $25 \mathrm{~mL}$ of $\mathrm{NaOH}(4,8$ and $12 \% \mathrm{w} / \mathrm{v})$ and then heated in an autoclave at $100{ }^{\circ} \mathrm{C}$ and $15 \mathrm{psi}$ for $1 \mathrm{~h}$. Also, $2.5 \mathrm{~g}$ of the powder was mixed in $25 \mathrm{~mL}$ of $\mathrm{NH}_{4} \mathrm{OH}(4,8$ and $10 \% \mathrm{w} / \mathrm{v})$ and then heated in an autoclave at $100{ }^{\circ} \mathrm{C}$ and $15 \mathrm{psi}$ for $1 \mathrm{~h}$. On the other hand, $1 \mathrm{~g}$ of the powder was mixed in $100 \mathrm{~mL}$ of $\mathrm{NH}_{4} \mathrm{OH}(6,8$ and $10 \% \mathrm{w} / \mathrm{v})$ in a water bath at $100{ }^{\circ} \mathrm{C}$. After $1 \mathrm{~h}$ of reaction, the solid fraction $(\mathrm{SF})$ was washed with distilled water until the $\mathrm{pH}$ became neutral, and dried at $90{ }^{\circ} \mathrm{C}$ overnight. Both solid fractions (SF) and liquid fractions (LF) were collected and stored for acid treatment prior to analysis.

\section{Acid treatment}

A total of $0.2 \mathrm{~g}$ resultant SF was added into $5 \mathrm{~mL}$ of $\mathrm{CH}_{3} \mathrm{COOH}(10,30,50$ and $100 \% \mathrm{w} / \mathrm{v})$ and underwent reaction by using a microwave reactor system (Explorer PLS, Focused Synthesis Instrumentation). The treatment was performed at 110 ${ }^{\circ} \mathrm{C}$ for $15 \mathrm{~min}$. Later, the samples were washed with distilled water until they were neutralised, and then dried at $90{ }^{\circ} \mathrm{C}$ overnight. The samples were labelled as $10 \%$ AA OPTF, 30\% AA OPTF, 50\% AA OPTF, and $100 \%$ AA OPTF, and stored in a desiccator before analysis.

\section{Delignification}

The concentration of lignin in the LF was measured by a spectrophotometer (JENWAY UV-Vis 7315) at $230 \mathrm{~nm}$. Meanwhile, the determination of the lignin content in the SF was examined according to the standard method described in TAPPI T 222.

\section{Fourier-transform infrared spectroscopy (FTIR)}

The FTIR spectra of $3 \mathrm{mg}$ untreated, alkali pretreated and acid-treated OPTF were recorded using an FTIR spectrometer (Perkin Elmer Spectrum 400) to observe the changes in the functional group. The transmittance mode and a scanning number of 32 s were selected in the range from 4000 to $600 \mathrm{~cm}^{-1}$. The spectra were normalised to 1 in the absorption band from 4000 to $600 \mathrm{~cm}^{-1}$. The ratio of lignin to cellulose, $\mathrm{R}$, of the untreated, alkali pretreated and acid-treated OPTF was determined as follows: $R=\left(A_{1504}\right.$ $\left.{ }_{1507}\right) /\left(\mathrm{A}_{1371-1374}\right)$, as the area ratio of $1504-1507 \mathrm{~cm}^{-1}$ $\left(\mathrm{A}_{1504-1507}\right)$ and $1371-1374 \mathrm{~cm}^{-1}\left(\mathrm{~A}_{1371-1374}\right)$ bands.

\section{X-ray diffraction (XRD)}

The crystallinity index (CrI) and crystallite size (L) of the untreated, alkali pretreated and acid-treated 
OPTF were characterised using an XRD (Bruker D8 Advance Madison, WI, USA). The XRD was performed using radiation of $\mathrm{Cu} \mathrm{K} \alpha=1.5458 \AA$ at a diffraction angle $(2 \theta)$ ranging from 10 to $60^{\circ}$. The diffraction profiles were carried out with a Gaussian function to determine the $\mathrm{CrI}$ of the samples. The $\mathrm{CrI}$ of the samples were determined using Bruker Advanced X-Ray Solutions software, DIFFRAC ${ }^{\text {PLUS }}$ Evaluation (EVA) by: $\mathrm{CrI}(\%)=\mathrm{A}_{\text {Crystal }} / \mathrm{A}_{\text {Total }}$. The crystallite size $(\mathrm{L})$ of the samples was calculated using the Scherrer equation: $\mathrm{L}=\mathrm{K} \lambda / \beta \cos \theta$, where $\mathrm{K}$ represents a constant value of $0.94, \lambda$ is the $\mathrm{X}$-ray wavelength of $0.1542 \mathrm{~nm}, \beta$ is the half-height width of the diffraction band, and $\theta$ is the Bragg angle that corresponds to the (002) plane.

\section{Viscosity-average molecular weight $\left(M_{\eta}\right)$}

The viscosity-average molecular weight $\left(M_{\eta}\right)$ of the untreated, alkali pretreated and acid-treated OPTF was determined in a cadoxen solution at a temperature of $25{ }^{\circ} \mathrm{C}$, using an Ubbelohde tube capillary viscometer. The samples were dissolved at a concentration of $3 \times$ $10^{-3}$ g.mL $\mathrm{mL}^{-1}$ and diluted for five times to achieve a concentration ranging from 1 to $3 \times 10^{-3}$ g. $\mathrm{mL}^{-1}$. The intrinsic viscosities [ $\eta$ ] of the OPTF were measured according to Kraemer and Huggins' equation by extrapolating the graph to zero concentration (c): $\eta_{\mathrm{sp}} / \mathrm{c}$ $=[\eta]+\hat{k}_{K}[\eta] 2 c$ and $\ln \eta_{\mathrm{sp}} / \mathrm{c}=[\eta]+\mathrm{k}_{\mathrm{K}}[\eta] 2 \mathrm{c}$, where $\mathrm{k}_{\mathrm{K}}$ is a constant with values lower than 1.0 for the Kraemer equation, while $\hat{k}_{\mathrm{H}}$ is a constant with values between 0.33 and 0.8 for the Huggins equation, and $\eta_{\mathrm{sp}} / \mathrm{c}$ is the specific viscosity of the sample.

\section{RESULTS AND DISCUSSION Delignification}

Table 1 shows the results for lignin concentration and AIL percentages obtained after the alkali pretreatment. The lignin concentration was found to be higher, when a high concentration of the pretreatment agent was used; this is applicable for sodium and ammonia-based alkali. Using $\mathrm{NaOH}$, the extracted OPTF lignin increased from 10273.4 to $10685.4 \mathrm{mg} . \mathrm{L}^{-1}$ and from 62.5 to $2094.0 \mathrm{mg} . \mathrm{L}^{-1}$ using $\mathrm{NH}_{4} \mathrm{OH}$; $\mathrm{NaOH}$ treatment led to the highest lignin removal. This is because $\mathrm{NaOH}$ is classified as a strong base, thus having higher reactivity than $\mathrm{NH}_{4} \mathrm{OH}$. The $\mathrm{OH}^{-}$from $\mathrm{NaOH}$ showed the presence of a stronger agent to attack the ester and/or ether linkages between the: (i) carbohydratecarbohydrate; (ii) carbohydrate-lignin; and (iii) lignin-lignin (Fig. 1). ${ }^{25}$ A study done by Minmunin et al. ${ }^{26}$ reported that $\mathrm{NaOH}$ has a better ability to disrupt the biomass cell wall and is capable of eliminating $63.4 \%$ of lignin from bana grass.

On the other hand, the OPTF lignin was significantly higher when extracted in the autoclave rather than in the water bath. As the $\mathrm{NH}_{4} \mathrm{OH}$ concentration was increased from 4 to $12 \%$ in the autoclave treatment, the lignin concentration also increased from 881.2 to 2094.0 $\mathrm{mg} . \mathrm{L}^{-1}$. However, the removal of lignin in the water bath treatment showed insignificant changes, namely, between 62.5 to $64.0 \mathrm{mg} . \mathrm{L}^{-1}$. Autoclaving causes the sample to experience rapid thermal expansion, ${ }^{27}$ which helps in the disintegration of the OPTF. Conversely, the heat was transferred directly and only contacted in the base of the sample by using the water bath. Besides that, the effectiveness of removing lignin was further assisted by the pressure developed in the autoclave process at 15 psi. Pressure causes the disassembly of the OPTF structure, allowing extensive penetration of the alkali to break the bonds between lignin and cellulose. ${ }^{28}$

Table 1

Extracted lignin concentration and AIL in untreated and alkali pretreated OPTF

\begin{tabular}{lcc}
\hline Samples & $\begin{array}{c}\text { Lignin concentration } \\
(\mathrm{mg} / \mathrm{L})\end{array}$ & AIL (\%) \\
\hline $\mathrm{OPTF}$ & - & $20.7 \pm 0.7$ \\
$4 \% \mathrm{NaOH}^{\mathrm{a}}$ & 10273.4 & $16.6 \pm 0.5$ \\
$8 \% \mathrm{NaOH}^{\mathrm{a}}$ & 10479.6 & $10.8 \pm 0.4$ \\
$12 \% \mathrm{NaOH}^{\mathrm{a}}$ & 10685.4 & $7.8 \pm 0.6$ \\
$4 \% \mathrm{NH}_{4} \mathrm{OH}^{\mathrm{a}}$ & 881.2 & $18.8 \pm 0.7$ \\
$8 \% \mathrm{NH}_{4} \mathrm{OH}^{\mathrm{a}}$ & 2007.9 & $18.4 \pm 0.2$ \\
$12 \% \mathrm{NH}_{4} \mathrm{OH}^{\mathrm{a}}$ & 2094.0 & $15.8 \pm 0.4$ \\
$4 \% \mathrm{NH}_{4} \mathrm{OH}^{\mathrm{b}}$ & 62.5 & $14.8 \pm 0.5$ \\
$8 \% \mathrm{NH}_{4} \mathrm{OH}^{\mathrm{b}}$ & 64.0 & $14.2 \pm 0.6$ \\
$12 \% \mathrm{NH}_{4} \mathrm{OH}^{\mathrm{b}}$ & 63.5 & $18.2 \pm 0.1$ \\
a autoclave; ${ }^{\mathrm{b}}$ water bath & &
\end{tabular}




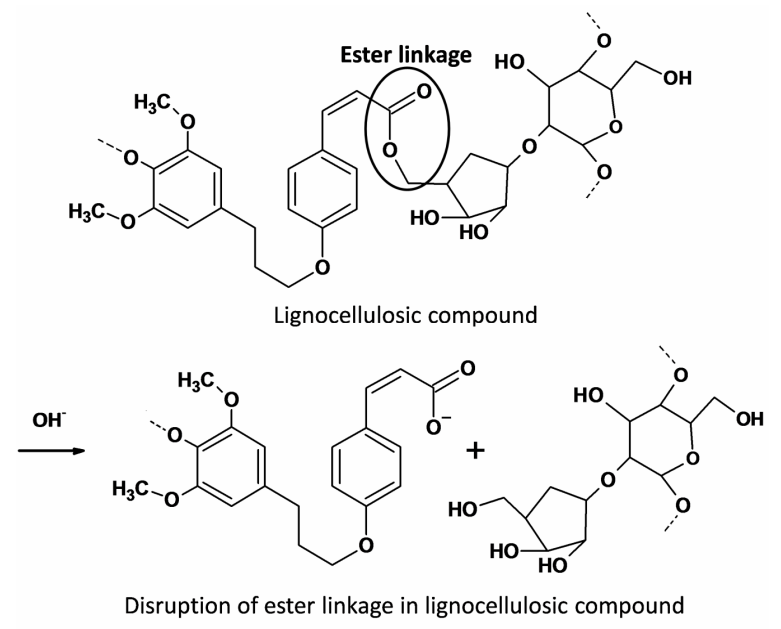

Figure 1: $\mathrm{NaOH}$ attack during pretreatment

The sample in the water bath was said not to be entirely surrounded in all directions by the alkali, hence, it only removed a small amount of lignin. This finding is supported by a study by

Assessing the acid insoluble lignin, AIL, is a method to determine the lignin in the fibres that is insoluble in sulfuric acid. Based on Table 1, the AIL content of untreated OPTF was $20.7 \%$. It was observed that the AIL content dropped from 16.6 to $7.8 \%$ with increasing $\mathrm{NaOH}$ concentration, indicating that higher lignin removal occurred. However, the percentage of reduction was less pronounced with the $\mathrm{NH}_{4} \mathrm{OH}$ treatment either by using the autoclave (18.8 to $15.8 \%)$ or by the water bath $(14.2$ to $18.2 \%)$. From all the alkali pretreatment methods, $\mathrm{NaOH} 12 \%$ in the autoclave was the best condition for delignification, thus the sample subjected to this optimised method was then subjected to an acetic acid (AA) treatment.

\section{Functional groups analysis}

Figure 2 shows the FTIR spectra of the OPTF, $\mathrm{NaOH}$ pretreated and AA treated OPTF. The spectrum of the untreated OPTF is different from that of the treated OPTF, but among the AA treated samples, the patterns of the spectra are similar. The peak at $3339 \mathrm{~cm}^{-1}$ represents the $\mathrm{OH}$ stretching at $\mathrm{C} 6$ position, ${ }^{29}$ while the peak observed at $2900 \mathrm{~cm}^{-1}$ stands for $-\mathrm{CH}$ stretching of methylene groups in cellulose. ${ }^{30}$ The $\mathrm{C}=\mathrm{O}$ stretching peak can be seen at $1750 \mathrm{~cm}^{-1}$, which is assigned to uronic and ester groups in the hemicellulose or ester groups found in $p$-coumaric acid of lignin. ${ }^{31,32}$ This peak reduced after the
Barua and Kalamdhad, ${ }^{21}$ which demonstrated better delignification, of $50 \%$, for water hyacinth using the autoclave treatment, as compared to that using the water bath one (45\%).

alkali and acid treatments, suggesting that the interruption of the lignin-carbohydrate linkages has occurred. Subsequently, this phenomenon has improved the cellulose digestibility. ${ }^{33}$ The peak at $1640 \mathrm{~cm}^{-1}$ was assigned to the carboxylate groups, while the peak at $1505 \mathrm{~cm}^{-1}$ was attributed to the polymer structure of the aromatic lignin group $(\mathrm{C}=\mathrm{C}){ }^{32}$ The functional group of $\mathrm{C}-\mathrm{O}-\mathrm{C}$ corresponds to the ether groups in lignin, which are present at $1250 \mathrm{~cm}^{-1}$ and $1050 \mathrm{~cm}^{-1} .^{34}$ The reduction of this peak after the alkali and acid treatments was correlated with the partial removal of lignin in the OPTF, as the ether groups between lignin and cellulose were broken. Next, the peak at $1371 \mathrm{~cm}^{-1}$ was assigned to the cellulose crystallinity, indicating $-\mathrm{CH}$ bending. ${ }^{35}$ The peak at $913 \mathrm{~cm}^{-1}$ was ascribed to $\beta$-glycosidic bonds, as well as to the amorphous area of the cellulose. ${ }^{8}$

The changes during the AA treatment have been confirmed by determining the lignin-tocellulose ratio of the samples. The band area at $1504-1507 \mathrm{~cm}^{-1}$, assigned to the total content of the lignin component (aromatic skeletal vibration), and at $1371-1374 \mathrm{~cm}^{-1}$, representing the $\mathrm{C}-\mathrm{H}$ in cellulose, was measured. Table 2 shows the ratio of lignin to cellulose, $\mathrm{R}$, of the OPTF before and after the treatment. From the results, the R measured in the initial OPTF was 2.83 , this is due to the presence of a high amount of lignin. However, the ratio decreased from 2.78 
to 1.32 after OPTF underwent the alkali and AA treatment, respectively. This proves the decrement in the lignin content caused by the disruption and disintegration of the OPTF.

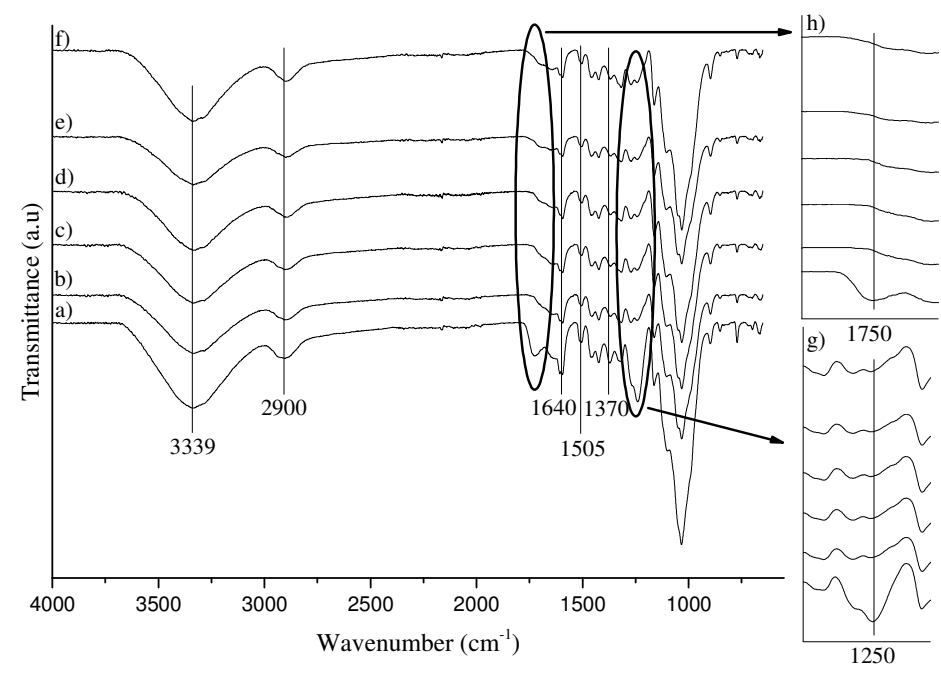

Figure 2: FTIR spectra of a) OPTF, b) NaOH pretreated OPTF, c) $10 \%$ AA OPTF, d) $30 \%$ AA OPTF, e) 50\% AA OPTF, f) $100 \%$ AA OPTF, g) functional group of C-O-C related to ether group, h) functional group of $\mathrm{C}=\mathrm{O}$ related to carbonyl group

Table 2

Decreased ratio of lignin to cellulose (R) of OPTF after alkali pretreatment and acid treatment

\begin{tabular}{lc}
\hline Samples & $\mathrm{R}\left(\mathrm{A}_{1504-1507} / \mathrm{A}_{1371-1374}\right)$ \\
\hline OPTF & 2.83 \\
NaOH pretreated OPTF & 2.78 \\
$10 \%$ AA OPTF & 2.76 \\
$30 \%$ AA OPTF & 1.71 \\
$50 \%$ AA OPTF & 1.57 \\
$100 \%$ AA OPTF & 1.32 \\
\hline
\end{tabular}

\section{Crystallinity analysis}

Figure 3 shows the $\mathrm{X}$-ray diffractogram of the OPTF samples in this study. The analysis reveals that all the samples presented a major peak at $22^{\circ}$ and a minor peak at $16^{\circ}$. These two peaks are labelled in the diffractogram, and assigned to the crystallographic planes of (200) and (110), respectively. Both peaks are correlated with the crystalline structure of cellulose type $\mathrm{I}^{36}$ As observed in the X-ray diffractogram, the intensity of the major and minor peaks increased with the increasing concentration of AA, suggesting that the AA treatment is able to enhance lignin and/or hemicellulose removal from OPTF. ${ }^{37}$

The relative amount of the crystalline region can be estimated by the CrI values from the XRD, as indicated in Table 3. The CrI of OPTF was $30.3 \%$ and reduced to $17.6 \%$ upon the alkali pretreatment. This is related to the removal of lignin from the sample. However, CrI increased gradually from $17.6 \%$ to $24.4 \%$ with increasing AA concentration from 10 to $100 \%$. The high CrI indicates that more accessible amorphous regions in cellulose were removed by the AA treatment, leading to a realignment of the cellulose molecules. Similar results have been reported by Padzil et al. ${ }^{38}$ showing that the CrI of acid-treated kenaf increased from 15 to $22 \%$.

The results for the crystallite size, L, of the OPTF are tabulated in Table 3. The initial $\mathrm{L}$ of OPTF was $3.02 \mathrm{~nm}$ and it increased to $3.63 \mathrm{~nm}$ after the alkali pretreatment. As the AA concentration increased, the $\mathrm{L}$ value also increased from 3.63 to $3.81 \mathrm{~nm}$. The alkali pretreatment helps in the removal of lignin, which eventually releases the individual cellulose 
BALQIS AZ-ZAHRAA NORIZAN et al.

crystallite. The increased $\mathrm{L}$ and $\mathrm{CrI}$ values upon amorphous regions of the OPTF cellulose.

acid treatment were due to the reduction in the

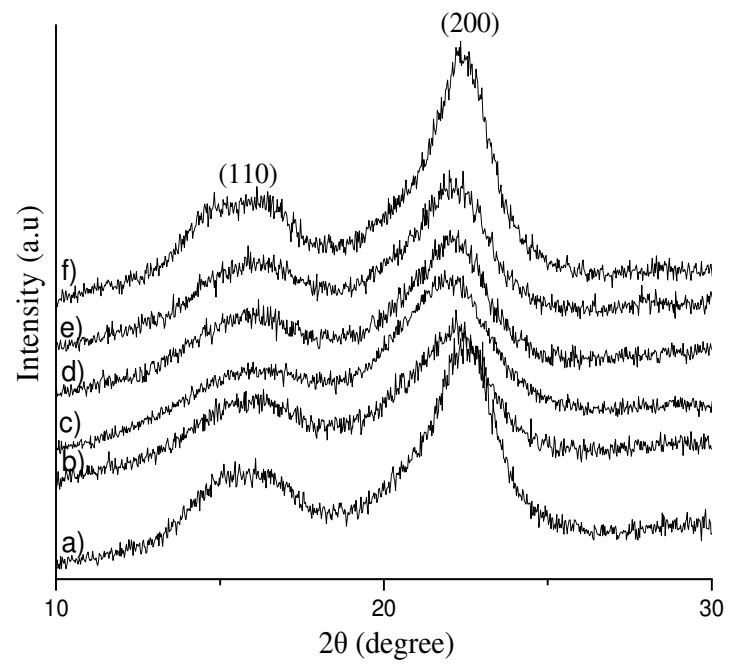

Figure 3: X-ray diffractogram of a) OPTF, b) NaOH pretreated OPTF, c) 10\% AA OPTF, d) $30 \%$ AA OPTF, (e) $50 \%$ AA OPTF, (f) $100 \%$ AA OPTF

Table 3

$\mathrm{CrI}$ and $\mathrm{L}$ values of OPTF after alkali pretreatment and acid treatment

\begin{tabular}{lcc}
\hline Samples & $\mathrm{CrI}(\%)$ & $\mathrm{L}(\mathrm{nm})$ \\
\hline OPTF & 30.31 & 3.02 \\
NaOH pretreated OPTF & 17.64 & 3.63 \\
10\% AA OPTF & 18.16 & 3.65 \\
30\% AA OPTF & 19.42 & 3.70 \\
50\% AA OPTF & 21.61 & 3.75 \\
100\% AA OPTF & 24.42 & 3.81 \\
\hline
\end{tabular}

Table 4

Reduction of viscosity-average molecular weight, $\mathrm{M}_{\eta}$ of OPTF after alkali pretreatment and acid treatment

\begin{tabular}{lc}
\hline Samples & $\mathrm{M}_{\eta}\left(\mathrm{x} 10^{4}\right)$ \\
\hline OPTF & $13.01 \pm 0.3$ \\
NaOH pretreated OPTF & $9.23 \pm 0.7$ \\
10\% AA OPTF & $4.52 \pm 0.5$ \\
30\% AA OPTF & $4.27 \pm 0.6$ \\
50\% AA OPTF & $3.01 \pm 0.7$ \\
$100 \%$ AA OPTF & $2.36 \pm 0.4$ \\
\hline
\end{tabular}

This is because the amorphous regions are easily disrupted, forcing the cellulose to reorganise and form larger crystallite sizes. This result is in good agreement with Gurgel et al., ${ }^{39}$ who showed that L increased over time. This increasing trend of $\mathrm{L}$ suggests that a more dense cellulose crystalline structure was present after the amorphous regions were removed during the AA treatment.

\section{Viscosity-average molecular weight}

The viscosity-average molecular weight values, $\mathrm{M}_{n}$, of $\mathrm{OPTF}, \mathrm{NaOH}$ pretreated and AA treated OPTF are summarised in Table 4. The initial $\mathrm{M}_{\mathrm{n}}$ for OPTF $\left(13.01 \times 10^{4}\right)$ was higher compared to that of the alkali pretreated one ( 9.23 $\times 10^{4}$ ). The finding depicted that the alkali pretreatment has led to lignin reduction, hence, reduced the $M_{\eta}$ value. Furthermore, the increased 
AA concentration resulted in a further reduction in $\mathrm{M}_{\eta}$ to $2.36 \times 10^{4}$. AA treatment promotes the depolymerisation of cellulose chains as the chains are broken down. Consequently, this damages the chain lengths ${ }^{40}$ and makes cellulose susceptible to be converted into other valuable materials. According to Lelekakis et al. ${ }^{41}$ the protonation of cellulose will take place upon the addition of acid, hence initiating the inter- and intramolecular chain-

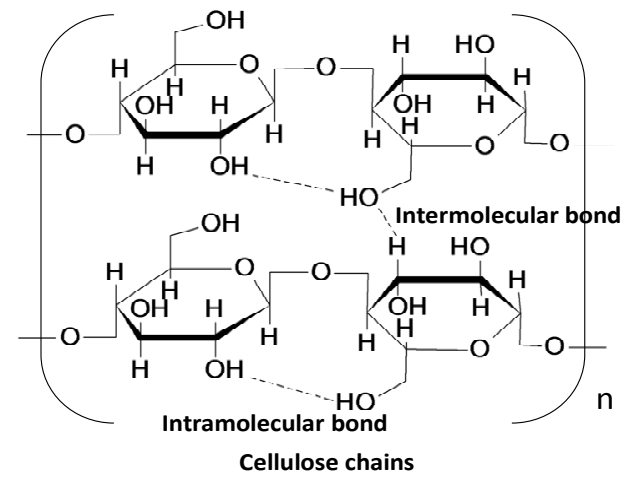

Figure 4: Reaction of cellulose with acid $\left(\mathrm{H}^{+}\right)$

\section{CONCLUSION}

Alkali pretreatment in $\mathrm{NaOH}$ solution, by the autoclaving system, can delignify OPTF more efficiently. At a range of $4-12 \% \mathrm{NaOH}$, the pretreatment process is able to decrease the OPTF lignin content from 20 to $62 \%$. The peak reduction in FTIR suggested that the ether groups between lignin and cellulose were broken because of the stronger $\mathrm{OH}^{-}$ion attack. In addition, the $\mathrm{R}$ value of the OPTF was reduced from 2.78 to 1.32 , as the concentration of AA increased from 10 to $100 \%$. However, the $\mathrm{CrI}$ increased gradually from $17.64 \%$ to $24.42 \%$. The increased $\mathrm{L}$ and $\mathrm{CrI}$ values upon AA treatment were due to the reduction in the amorphous regions of OPTF cellulose, forcing the cellulose to reorganise and form larger crystallite sizes. AA treatment causes chain-breaking in cellulose, hence, allowing amorphous cellulose digestibility and cellulose realignment as the $\mathrm{M}_{\eta}$ values decreased from 4.52 to $2.36 \times 10^{4}$.

ACKNOWLEDGEMENT: The authors would like to acknowledge the financial support given by the Ministry of Higher Education, Malaysia, through the research university grant GUP-2017114, and the Centre for Research and Instrumentation Management (CRIM), UKM, for the testing services. breaking, as proposed in Figure 4. The cellulose will accept a proton from the acid and share an electron with the oxygen on the cellulose. After the proton has been donated, the water molecule will attack the carbon on the cellulose, causing the chain to break. Lower $\mathrm{M}_{\eta}$ in AA treated OPTF confirms the occurrence of cellulose chainbreaking, as cellulose depolymerisation depends on the concentration of acids.

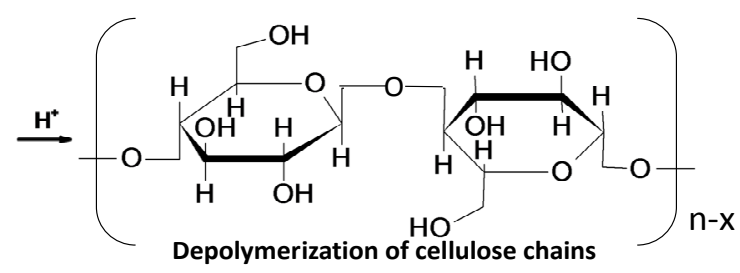

\section{REFERENCES}

M. Bansal, G. S. Chauhan, A. Kaushik and A. Sharma, Int. J. Biol. Macromol., 91, 887 (2016), http://dx.doi.org/10.1016/j.ijbiomac.2016.06.045

2 J. P. de Oliviera, G. P. Bruni, K. O. Lima, S. L. M. E. Halal, G. S. de Rosa et al., Food Chem., 221, 153 (2017), http://dx.doi.org/ 10.1016/j.foodchem.2016.10.048

3 L. Y. Xiang, M. A. P. Mohammed and A. S. Baharuddin, Carbohyd. Polym., 148, 11 (2016), http://dx.doi.org/10.1016/j.carbpol.2016.04.055

4 J. Shokri and K. Adibkia, in "Cellulose - Medical, Pharmaceutical and Electronic Applications", edited by T. van de Ven and L. Godbout, IntechOpen, 2013, p. 47, http://dx.doi.org/10.5772/55178

B. A. Norizan, N. S. Mahadi, N. N. M. Nizam, S. Zakaria, M. F. Daud et al., Malaysian J. Anal. Sci., 22, 915 (2018), http://dx.doi.org/10.17576/mjas-20182205-20

6 N. Spanic, V. Jambrekovic and M. Klaric, Cellulose Chem. Technol., 52, 163 (2018), http://www.cellulosechemtechnol.ro/pdf/CCT34(2018)/p.163-169.pdf

7 C. S. Goh, K. T. Tan, K. T. Lee and S. Bhatia, Bioresour. Technol., 101, 4834 (2010), http://dx.doi.org/10.1016/j.biortech.2009.08.080

8 J. Zhang, Y. S. Choi, C. G. Yoo, T. H. Kim, R. C. Brown et al., ACS Sustain. Chem. Eng., 3, 293 (2014), https://doi.org/10.1021/sc500664h 
9 Z. Jin, K. S. Katsumata, T. B. T. Lam and K. Iiyama, Biopolymers, 83, $103 \quad$ (2006), https://doi.org/10.1002/bip.20533

10 D. Klemm, B. Heublein, H. P. Fink and A. Bohn, Angew. Chem. Int. Ed. Engl., 44, 3358 (2005), https://doi.org/10.1002/anie.200460587

11 L. Kupianen, PhD Thesis, University of Oulu, 2012,

http://jultika.oulu.fi/files/isbn9789526200033.pdf

12 R. Rinaldi and F. Schuth, ChemSusChem, 2, 1096 (2009), https://doi.org/10.1002/cssc.200900188

13 S. P. Govumoni, S. Koti, S. Y. Kothagouni, S. Venkateshwar and V. R. Linga, Carbohyd. Polym., 91, 646

(2013),

https://doi.org/10.1016/j.carbpol.2012.08.019

14 Y. Zhang, R. Zhu and W. Yu, Cellulose Chem. Technol., 51, 103 (2017), http://www.cellulosechemtechnol.ro/pdf/CCT12(2017)/p.103-108.pdf

15 S. X. Chin, C. H. Chia, Z. Fang, S. Zakaria, X. K. Li et al., Energ. Fuel, 28, 2589 (2014), https://doi.org/10.1021/ef402468z

16 A. L. Umagiliyage, R. Choudhary, Y. Liang, J. Haddock and D. G. Watson, Ind. Crop. Prod., 74, 977 (2015), https://doi.org/10.1016/j.indcrop.2015.05.044

17 S. Gan, F. N. M. Padzil, S. Zakaria, S. H. Chia, S. N. S. Jaafar et al., BioResources, 10, 2244 (2015), https://doi.org/10.15376/biores.10.2.2244-2255

18 T. H. Kim, R. Gupta and Y. Y. Lee, Methods Mol. Biol., 581, 79 (2009), https://doi.org/10.1007/978-160761-214-8_6

19 L. W. Lai and A. Idris, Renew. Energ., 99, 738 (2016), https://doi.org/10.1016/j.renene.2016.07.059

20 H. V. Lee, S. B. A. Hamid and S. K. Zain, Sci. World J., 2014, 1 (2014), http://dx.doi.org/10.1155/2014/631013

21 V. B. Barua and A. S. Kalamdhad, Bioresour. Technol., $\quad 227, \quad 147 \quad$ (2016), https://doi.org/10.1016/j.biortech.2016.12.036

22 S. B. Jamaldheen, K. Sharma, A. Rani, V. S. Moholkar and A. Goyal, Prep. Biochem. Biotech., 48, 457 http://dx.doi.org/10.1080/10826068.2018.1466148

23 S. M. Nomanbhay, R. Hussain and K. Palanisamy, J. Sustain. Bioenerg. Syst., 3, 7 (2013), http://dx.doi.org/10.4236/jsbs.2013.31002

24 Z. Zhu, C. A. Rezende, R. Simister, S. J. McQueenMason, D. J. Macquarrie et al., Biomass Bioenerg. J., 93, 269 (2016), https://doi.org/10.1016/j.biombioe.2016.06.017

25 A. A. Modenbach and S. E. Nokes, T. ASABE, 57, 1187 (2014), https://doi.org/10.13031/trans.57.10046

26 J. Minmunin, P. Limpitipanich and A. Promwungkwa, Waste Biomass Valor., 9, 2099 (2018), https://doi.org/10.1007/s12649-017-0002-2

27 K. Suresh, A. Ranjan, S. Singh and S. A. Moholkar, Ultrason. Sonochem., 21, 200 (2014), https://doi.org/10.1016/j.ultsonch.2013.07.010
28 M. A. Abdullah, M. S. Nazir, M. R. Raza, B. A. Wahjoedi and A. W. Yussof, J. Clean. Prod., 126, 686 (2016), http://dx.doi.org/10.1016/j.jclepro.2016.03.107 29 J. Lamaming, R. Hashim, C. P. Leh and O. Sulaiman, Carbohyd. Polym., 156, 409 (2017), http://dx.doi.org/10.1016/j.carbpol.2016.09.053

30 S. O. Amiandamhen, M. Meincken and L. Tyhoda, Wood Sci. Technol., 52, $653 \quad$ (2018), https://doi.org/10.1007/s00226-018-0999-9

31 R. A. Ilyas, S. M. Sapuan, M. R. Ishak and E. S. Zainuddin, BioResources, 12, $8734 \quad$ (2017), https://doi.org/10.15376/biores.12.4.8734-8754

32 S. N. A. S. H. Hashim, S. Zakaria, C. H. Chia and S. N. S. Jaafar, Polym. Renew. Res., 9, 39 (2018), https://doi.org/10.1177/204124791800900103

33 Z. Cui, C. Wan, J. Shi, R. W. Sykes and Y. Li, Ind. Eng. Chem. Res., 51, $7153 \quad$ (2012), https://doi.org/10.1021/ie300487z

34 S. N. S. Jaafar, E. Haimer, F. Liebner, S. Bohmdorfer, A. Potthast et al., J. Biobased Mater. Bio., 5, $225 \quad$ (2011), https://doi.org/10.1166/jbmb.2011.1140

35 M. El-Sakhawy, S. Kamel, A. Salama and H. S. Tohamy, Cellulose Chem. Technol., 52, 193 (2018), http://www.cellulosechemtechnol.ro/pdf/CCT3-

4(2018)/p.193-200.pdf

36 J. Lamaming, R. Hashim, O. Sulaiman, C. P. Leh, T. Sugimoto et al., Carbohyd. Polym., 127, 202 (2015), http://dx.doi.org/10.1016/j.carbpol.2015.03.043

37 S. Sun, W. Chen, J. Tang, B. Wang, X. Cao et al., Biotechnol. Biofuels, 9, $217 \quad$ (2016), http://dx.doi.org/10.1186/s13068-016-0632-9

38 F. N. M. Padzil, S. Zakaria, C. H. Chia, S. N. S. Jaafar, H. Kaco et al., Carbohyd. Polym., 124, 164 (2015), http://dx.doi.org/10.1016/j.carbpol.2015.02.013

39 L. V. A. Gurgel, K. Marabezi, L. A. Ramos and A. A. d. S. Curvelo, Ind. Crop. Prod., 36, 560 (2012), https://doi.org/10.1016/j.indcrop.2011.11.009

40 D. C. Martino, J. L. Colodette, R. Chandra and J. Saddler, Wood Sci. Technol., 51, 557 (2017), https://doi.org/10.1007/s00226-016-0889-y

41 N. Lelekakis, J. Wijaya, D. Martin and D. Susa, IEEE Electr. Insul. M., 30, 19 (2014), https://doi.org/10.1109/MEI.2014.6804738 